\title{
Prioritising the cultural inclusivity of a rural mainstream health service for First Nation Australians: an analysis of discourse and power
}

\author{
Christina Malatzky, Raylene Nixon, Olivia Mitchell \& Lisa Bourke
}

\begin{abstract}
In the context of persisting health inequities within many multicultural and socially diverse countries like Australia, there is a call for health services to implement culturally inclusive systems and practices. Nowhere is this more important than in regional, rural and remote Australia where consumers are diverse, health services are scarce, and services designed for particular groups of the population are lacking. Drawing on interviews with 20 staff of a rurally-based, mainstream community health service, this article examines the role of discourse in transition to a culturally inclusive health centre. In doing so, the power struggles inherent in such a process are highlighted. The article contends that improvements in the health outcomes of First Nation and culturally Other groups within the Australian population is contingent upon systematic resistances that disrupt and re-arrange existing dominant discourses. This calls for disruption of current race relations in both broader social fields as well as those supporting biomedical assumptions about the delivery of healthcare in the mainstream health sector. Alternative discourses must be promoted in both these fields.
\end{abstract}

\section{Keywords}

Mainstream rural health institutions, cultural exclusion/inclusion, First Nation Australians, power struggles, dominant/counter-discourses, critical reflection 


\section{Introduction}

Like other nations, Australians who are sickest are also those who are systematically marginalised in, and largely excluded from, dominant social, economic and political institutions. To address the resulting health inequities, there have been calls, using various terminology (Grant, Parry, \& Guerin, 2013), for health services to implement culturally inclusive systems and practices. In health literature, cultural inclusivity refers to the creation of inherently accessible services in which all people, but most especially those who are commonly excluded from mainstream health services, feel safe and welcomed (J.-F. Levesque, Harris, \& Russell, 2013; Newman, Persson, Paquette, \& Kidd, 2013). The healthcare provided in culturally inclusive health services is responsive to patient/client need and delivered in ways that demonstrate an acceptance of and respect for the cultural and social identities of its users (Dwyer, O'Donnell, Willis, \& Kelly, 2016; Gibson, Lee, \& Crabb, 2016; J.-F. Levesque et al., 2013).

The provision of this kind of healthcare involves a relational organisational culture (Azmat, Fujimoto, \& Rentschler, 2015) in which health service staff can 'relate across cultures' (Dwyer et al., 2016). To achieve this, an organisation must critically examine the cultural orientations, assumptions, beliefs and values operating within its service environment (Browne et al., 2016; Dreamson, Thomas, Lee Hong, \& Kim, 2017). Essentially, normative thinking about difference and the discrimination and exclusion it fosters can be challenged, wrestled with, and responded to in meaningful, constructive ways (Allan \& Smylie, 2015; Dwyer et al., 2016). This is a difficult and complex undertaking because it challenges mainstream institutional approaches to the delivery of healthcare (Allan \& Smylie, 2015). Mainstream approaches are predominately designed within a standardising medical model and based on the logics of those belonging to the dominant cultural group (Durey, 2015). Yet in a multicultural, socially diverse country like Australia, there are a multitude of cultural and 
social groups and each have different needs and criteria for what constitutes an appropriate, safe and quality health service (J.-F. Levesque et al., 2013), which are largely ignored in the current healthcare 'maze' (Collyer, Willis, \& Lewis, 2017). To adopt a culturally inclusive approach to the delivery of healthcare requires a shift in thinking and practice from within mainstream, dominant institutions.

Such a shift is nowhere more important than in rural communities where consumers are diverse, health services lacking and services designed for particular population groups tend to be few (Malatzky \& Bourke, 2017; Waldram et al., 2006). Rural Australia is home to many First Nation Australians who have significantly poorer health outcomes than non-First Nation Australians (Australian Institute of Health and Welfare, 2016). This health disparity evidences the continuing implications of colonialisation, historical injustice and trauma, socioeconomic exclusion, and systemic racism and discrimination on the health and wellbeing of First Nation Australians (Durey, 2015). Systematic and serious structural change, including to the health, education, housing and justice systems, and employment and land management sectors are needed to rupture current social and political relations between the First Nations of Australia and the Commonwealth of Australia (Davis, 2015). The provision of culturally inclusive healthcare represents one important component in redressing social, economic and health inequities of First Nation Australians.

To provide culturally inclusive healthcare to First Nation rural populations, local health institutions need to reflect critically upon the cultural truths that underpin their own systems, including biomedical perspectives on healthcare, health policies and often rigid and divisive funding structures as well as the economics of healthcare that currently subsidise private practice (Collyer et al., 2017). In order to imagine how things could be done differently (Ball, 2017), mainstream health institutions need to grapple with how certain dominant ideas and 
ways of thinking inform practice and what this means for the accessibility and effectiveness of these services in engaging marginalised and disadvantaged groups. Understanding the role of discourse in transition to culturally inclusive healthcare practice is critical to facilitating the needed shift within the mainstream health sector. In this paper we aim to explore and understand the enactment of discourses surrounding cultural inclusion at a particular point in time through interviews with staff working in a regionally-based community health service. Specifically, our analysis concentrates on the power struggles evidenced in the reproduction of and resistance to key social and healthcare discourses.

The first part of our analysis examines the counter-discourses drawn on by the leaders of the health service, especially in relation to the rationale for cultural inclusion. Counter-discourses constitute those discourses that run counter to (or resist) dominant, normalising discourses and through which alternate practices can be legitimised (Armstrong \& Murphy, 2012; Foucault, 1995). Others have explained the notion of counter-discourse as 'transformative action' (Riessman, 2000, p. 122) or a 'rhetorical strategy of resistance' (Murphy, 2003, p. 443). Although, as Foucault and others (Lupton, 1995) have argued, the extent to which counter-discourses can be accepted as truth is limited by the particular cultural and social contexts in which they are produced. Thus, the second part of our analysis examines some of the limitations of these leadership acts, evidenced in participants' narratives. The analysis highlights the complexities of enacting cultural inclusivity in mainstream health services.

In recognition of the power of language and its consequences for representation (Foucault, 1972), the authors have deliberately chosen to use the term 'First Nation Australian/s' throughout the paper. The land mass known as 'Australia' comprises hundreds of Nations of its First Peoples - that is, the people who lived on and cared for the land tens of thousands of years before White colonisation - each of which has its own language, customs, beliefs and ways of living. 'First Nation Australians' refers to all members of these First Nations. There 
are differing views within the local community when it comes to preferred terms and there is no consensus between different groups. Thus, the authors have chosen to move away from terms that can carry associations with racial vilification and towards a term that clearly signifies the rightful status of First Nation peoples in the country of Australia and is most appropriate for resilient peoples who belong to the oldest cultures in the world (Poroch, 2012).

\section{Research Context}

The data drawn on in this article was produced in a study initiated with a regionally-based, mainstream community health service in Victoria, referred to here by the pseudonym Essential Community Health $(E C H)$. The region in which $E C H$ is based has the highest population of First Nation Australians outside the Melbourne metropolitan area, with estimates ranging up to $10 \%$ or 6,000 residents (Bourke \& Geldens, 2007). However, estimates are lower from Census and government agencies than those sourced from local First Nation organisations. $E C H$ is a not-for-profit, government-funded community health centre operating as a limited company. While the majority of clients accessing $E C H$ do not identify as First Nation, the service has gained a local reputation as a provider to whom First Nation clients can be referred if for whatever reason, the local ACCHO is not an option. Reporting to a Board, the CEO of ECH carries considerable influence over and responsibility for the development and execution of strategic plans and oversees all daily management decisions and operations, including those pertaining to service delivery, staffing and budget. According to its leaders, $E C H$ is on a self-initiated journey to improve its cultural inclusivity and provide marginalised health consumers with care they perceive they need.

Working from a social model of health with a focus on client-centred care, the service adopts the perspective that clients are experts in their own lives and health needs. Leaders at $E C H$ 
presented this approach as providing choice of service and addressing the needs of local residents who most need healthcare. It must be noted that community health services have a mandate to provide accessible public healthcare to disadvantaged and under-serviced groups; hence, leaders were fulfilling funding obligations. However, $E C H$ has encountered criticism: some influential figures in the community claim that the service has forgotten it is a 'mainstream' and not an 'Aboriginal' service. This suggests that ECH's approach goes beyond an agenda of simply meeting governmental and/or funding-related requirements.

Prior to this project being undertaken, there was an existing partnership between $E C H$ and the academic department to which the authors belong, involving students and research. Through this partnership, the topics of cultural inclusion, culturally safe organisations, and racism in the community emerged in discussions. Leadership at $E C H$ was interested in these topics as were the authors who work in the area of culture and ex/inclusion in rural health. It was mutually agreed that initial research be conducted to examine staff perspectives on, and responses to, the prioritisation of cultural inclusion at $E C H$.

\section{Methods}

Three of the authors, one of whom is First Nation Australian, conducted face-to-face, semistructured interviews with 20 individuals working at/with $E C H$. Interviews ranged from 20 to 120 minutes in length with an average duration of 44 minutes. A flexible interview schedule was used to guide conversations. Similar global questions pertaining to workplace environment, the general principle of cultural inclusion at $E C H$ and changes that may have occurred to improve cultural inclusivity were asked of all participants. However, the order and precise wording evolved with each interview (Richards, 2015). Interviewers concentrated more on areas or topics that were of particular interest to the individual participant and gave 
less time to other areas that were less applicable and/or engaging for the particular participant (Bloom, 1997).

For recruitment, interviewers were given a list of all current staff at the time of the study $(n=52)$. The list identified First Nation staff via an asterisk $(n=4)$. Interviewers requested that senior staff involved in collating this list remove the names of staff member/s who expressed a wish not to be contacted about the research and to replace these names with a numeral. However, no numerals appeared on the list, indicating that all staff were interested in being invited to participate in the study. Using the list, the First Nation author contacted the four staff at $E C H$ identifying as First Nation to see if they were interested in participating in the study. All consented to participate in the research and were interviewed by this researcher. These participants were given the option of being interviewed by either a First or non-First Nation interviewer/author given that it may (or may not, depending on context) be more culturally safe and appropriate for interviews with members of the First Nation community to be conducted by First Nation researchers (Penman, 2006). The remaining 16 participants were non-First Nation and included: the present and immediate past Chief Executive Officer (CEO) (referred to in this article as the 'Executive participants'), two Board members randomly selected from a total of six, and 12 non-First Nation staff, also randomly selected. To select these staff, SPSS generated 12 random numbers (from 52) that were matched to the corresponding names on the supplied list. The same procedure was followed to select two of 12 Board members. In total, 20 participants participated in an interview.

Both Executive participants had worked in various roles at $E C H$ for around a decade. One Board member had been serving for two years and the other for 11 years. Length of time at the service for First Nation and other non-First Nation staff interviewed varied (see Table 1). These staff participants held different roles in the service at the time of interview, including those pertaining to: youth outreach, family violence, Aboriginal Pathways, 
reception/administration, drug and alcohol, refugee counselling, financial counselling, clinical services and management. It should be noted that several participants, especially those who had worked at the service for three or more years, had previously held different positions at $E C H$.

Explicit conversations between the three different interviewers ensured that a consistent approach and similar protocol was followed in each interview (Rubin \& Rubin, 2012). Interviews were audio-recorded, assigned a number as a de-identification strategy and transcribed verbatim (Nikander, 2008). Transcripts were checked against audio-recordings by the first author to ensure accuracy and the removal of other potentially identifying information (e.g. references to participants' names in-text) and disseminated to all authors. The coding process, principally as described by Braun and Clarke (2013) as an iterative practice to gain a familiarity with data through a method of: reading and re-reading; generating initial codes; proceeding with multiple rounds of coding to revise, review and refine codes; identifying relationships between codes and categorising codes together accordingly; and then drawing these groupings together under broad foci based on the identification of further interrelationships between categories, was discussed in a team meeting by three of the authors, including the First Nation Australian author and the first author, who then proceeded to independently code the data. These authors then reconvened to discuss, compare and reconcile the coding of data as a team (Denzin \& Lincoln, 2011). Issues were raised, reflected on and discussed as the analysis was written up in reports and in this paper.

For this paper, further focussed analysis was then undertaken by the first author, informed by Foucault's ideas about power, conceptualised as analytical tools (Foucault in Macey, 1993), to identify data that involved participants' employment of discourses relating to cultural inclusion and further elucidate what the narratives of participants can tell us about the power 
struggles inherent in prioritising cultural inclusion within mainstream health institutions. This analysis involved repeatedly returning to both the coded data and original transcripts and reading and re-reading this material with the aim of discerning segments of data in which the (re)production of and/or resistance to dominant power relations could be identified and described (Gavey, 1997). The resulting analysis was reviewed and refined through team discussions.

\section{Findings}

\section{Resisting dominant relations of power in mainstream health services}

The discourse of the two Executive participants contested many dominant societal 'truths' and biomedical assumptions about the role and functioning of mainstream health services. The leaders of $E C H$ were well aware of the proportion of First Nation Australians living in the local area and that culturally safe and secure environments are essential for improving access to healthcare (Durey, 2010). These non-First Nation participants articulated a clear rationale for prioritising the cultural inclusivity of rural mainstream health services; it's about 'creat[ing] choice and equity of access' (Executive participant). Rather than using the existence of specialist First Nation health services such as Aboriginal Community Controlled Health Organisations (ACCHOs) to brush off the need for change to occur within mainstream services, the leaders of $E C H$ emphasised that, like other residents, First Nation Australians are entitled to choose from a range of health service providers:

I expect a first-class health service and so should everyone else in the community...it is about that empowerment, that you have the power to choose [emphasis added], the power to make complaints, the power to question... (Executive participant) I think when you go over to [a local ACCHO] and the quality of their health service...the quality should be everywhere...I mean they have the right to expect what everyone else does (Executive participant).

The logic for these participants was that everyone is entitled to a choice of services. This is particularly critical in rural areas where choice of services for all residents is already limited (Malatzky \& Bourke, 2017). Further, if mainstream health services are culturally appropriate 
for First Nation Australians, then these clients can choose to access either ACCHOs and/or mainstream services. There is no choice and no equity of access if mainstream health services are not culturally safe and secure for First Nation Australians. In this context, it should be acknowledged that the Australian public health system does not offer choice at the tertiary, acute level. Focusing on their immediate objectives, Executive participants argued that the $E C H$ existed to address health needs and clients should be able to use their service if they chose to do so.

To this end, Executive participants described initiating various changes within the service to create a culturally safe, inclusive environment, particularly for First Nation clients. These changes included reviewing pathways into the service for First Nation clients, and a strong focus on symbols. Executive participants expressed that symbols, such as the display of First Nation Australian flags and locally produced artwork 'create an aesthetic that [you have] to live up to...symbolism holds you to account'. Mandatory cultural competency training, delivered by a local provider, was also introduced for all staff, and First Nation staff were employed in reception and program-specific roles. For example, family violence and drug and alcohol programs had First Nation-specific as well as 'mainstream' job positions. Further, Executive participants described re-arranging usual team-based seating arrangements into multidisciplinary pods to encourage a cross-pollination of skills and cultural knowledge. In relation to overarching organisational structures related to cultural inclusion, Executive participants explained that:

We made a decision not to do a reconciliation action plan...we needed a cultural safety policy [that would outline] how we are going to behave. Instead of a plan, it was more around, you're actually going to be held accountable by policy because breaching our policy ends in disciplinary action, whereas a plan was a bit wishy washy for me (Executive participant).

This policy was preceded by what Executive participants described as a clear message to staff. 
I heard all these whispers around...the tearoom. I just said very clearly folks that if you're not interested in understanding the role that we play in supporting the progression of Aboriginal people in this community towards their own selfdetermination, then you're in the wrong place because I need to tell you the leadership team is (Executive participant).

While some observers could interpret much of this work to be leadership meeting funding requirements, Executive participants described particular personal backgrounds and experiences that indicated a genuine desire to create authentic change. These participants had seen the way that "white middleclass mainstream services approach working with Aboriginal communities and Aboriginal people', which they described as shaping their approaches as health service leaders.

[I saw] the way the service sector viewed and required us as [non-First Nation] workers to interact and work with Aboriginal communities and the way I conducted myself personally in those personal friendships, there was quite an incongruity between those two (Executive participant).

From the perspectives of these participants, it was their 'own experiences...that allowed me to shut my ignorant white mouth long enough to hear from them [the community] about how our agency should progress' (Executive participant). These participants reflected on their own personal histories.

I grew up alongside a lot of those European conflicts...they talk about ethnic cleansing and genocide and it's a horrible day when you, it dawns on you...that you're living on land that underwent an ethnic cleansing through colonising force and that to this day, that colonising force that was empowered by my ancestors and, you know, by me just through continuation, still having the same oppressive impact. So, you know, all of those things come together to help me understand or try and understand... (Executive participant).

In these accounts, Executive participants were drawing on alternative discourses to construct and promote a different set of values and concepts (see Lupton, 1994) to those dominantly operating within and informing mainstream approaches to the delivery of healthcare.

Unlike Executive participants however, many other non-First Nation staff participants were unable to engage with the rationale or prioritisation of cultural inclusion in a mainstream health service, most especially in relation to First Nation Australians at ECH. It became clear 
in the interviews that many participants were unable to articulate the changes made to the service as described by the Executive, and even fewer were able to engage in a discussion about what effect, if any, such changes had had on their practice. As we explore below, responses to the prioritisation of cultural inclusion amongst other non-First Nation staff ranged from confusion to counter-resistance.

\section{Embedding counter-discourses in mainstream health}

Executive participants may have been engaging counter-discourses in their narratives pertaining to cultural inclusion; however, many other non-First Nation staff were confused about, and at times rejected, the prioritisation of cultural inclusion at $E C H$ for First Nation Australians.

...I'm still not a $100 \%$ clear because we have [a local ACCHO]... why do we coexist with [the local ACCHO]...I don't know why people are, Indigenous clients are necessarily coming here when I would have thought [the local ACCHO] would be their first port of call (non-First Nation participant)

The problem for me, and I may be wrong...I think we have a very high focus on Indigenous culture, which in and of itself I'm not averse to, I think it's great, but I think we're leaning towards that area at the risk of positively discriminating against others (non-First Nation participant).

Relatedly, First Nation staff participants discussed their non-First Nation Australian

colleagues' lack of understanding about First Nation cultures, what it means to live as an First

Nation person and the historical and structural influences shaping the positionalities of First

Nation peoples today.

I think that they [non-First Nation staff] just need to give [emphasis added], they need to understand Aboriginal culture and what it means and you know, Aboriginal people live and breathe their culture every day (First Nation staff participant)

I think cultural safety's about acknowledging and accepting someone's culture and whether you want to call that different from the norm or not, it's up to yourself. But, I think to make an Aboriginal person, for me, to make me feel safe is showing that respect for my background, being mindful that my opinion will differ based on my history and experiences being brought up as an Aboriginal person [emphasis added] (First Nation staff participant). 
In these accounts, First Nation participants were articulating the need for First Nation colleagues and clients to be seen as different from a White norm, to be acknowledged and accepted as being different, and for health services to differentiate the manner in which care is delivered accordingly. This is particularly challenging in light of dominant discourses that represent Australia as a 'White' nation and do not acknowledge the historical and continuing struggle of First Nation Peoples to have the consequences of persistent denials of First Nation Peoples' sovereignty recognised (Moreton-Robinson, 2014). It also contradicts influential biomedical discourses in health that position clinical practice as distinct and separate from social relations, and thus assume that attempts to be blind to difference constitute equitable, inclusive practice (Baker \& Beagan, 2014).

Interviews with non-Executive participants found attitudes, practices and tensions inherently incongruent with the notion of cultural inclusion. For example, First Nation participants described times when they did not feel safe to express their views, particularly in relation to 'Indigenous issues' with their non-First Nation colleagues. Some of these First Nation participants reported actively disengaging and/or avoiding conversations in which such topics could be raised.

...I just turned around and said I'm not talking about it with you two, you two of all people I'm not talking about it with because I felt that it wouldn't have been fair, a fair conversation...I felt that I probably would have been attacked so I nipped it in the bud. I felt, rather than have that conversation and walk away upset, dissatisfied, then feeling that they've won or me feeling that I've won, I didn't want to be [inaudible] so basically said no to that conversation...I felt exhausted by the end of that week...But they're the things I need to prepare myself for mentally because sometimes it happens, I had to think about all this prior to what I've got in my head that has to come out, I need to think about sometimes the confrontation because it's possible (First Nation staff participant).

There was also an uncertainty and cautiousness about how to talk about 'race' amongst some non-First Nation participants, which was connected to not wanting to be perceived as racist. Thus, some non-First Nation participants remained 'silent' or at other times ended discussions that alluded to 'race' in some way. 
Interviewer: Do you think that Aboriginal people have a different understanding of health in general?

Non-First Nation participant: It's hard to, it's always touchy, and it's a touchy subject. Interviewer: Why is it touchy?

Non-First Nation participant: Well, I never want to say the wrong thing or make it sound like it's in the wrong way [laughter]...

Some non-First Nation participants lacked a language with which to articulate their thoughts; for example, using the term 'Australian clients' in juxtaposition to 'Indigenous clients', suggesting that 'Indigenous clients' somehow do not meet the accepted definition of 'Australian' and that participants did not know how to frame or talk about the cultural differences between First and non-First Nation client groups. In attempts to articulate what is 'different' about First Nation kinship structures and family relations, another stated: 'I shouldn't say controlling, but, I don't know how to...' (non-First Nation participant). In this excerpt, the participant is attempting to articulate that a greater sense of obligation within First Nation family networks can, from a White perspective, distract or prevent a client's 'progress' in their health-related journey. It was difficult for this non-First Nation participant not to locate the 'problem' within First Nation culture rather than Western biomedical healthcare practices that treat healthcare users and practitioners as if they are somehow divorced from a socio-cultural context (Collyer et al., 2017; Malatzky \& Bourke, 2017).

Among narratives of non-First Nation staff, there was a sense of wanting to convey all is well within the service in relation to racial tensions. Non-First Nation participants in particular were presenting a clean picture of the service through the use of protocol and procedural language. Further, inconsistencies emerged between non-First Nation participants' accounts. For example, one non-First Nation participant indicated that no complaints had been made about a particular change within the service when another non-First Nation participant 
reported that they had complained. There was a sense of something unspoken in these interviews: it was clear these were sensitive issues that needed to be discussed carefully.

Interviews with First Nation staff participants were more successful at exploring some of these interactions. First Nation staff participants were aware of the avoidance articulated above, of the way that some non-First Nation staff 'tippy toe [around race-related talk] because they're worried about the way they talk about Aboriginal people or what's the proper terminology they should use'. However, some First Nation staff participants expressed that they 'don't want to be targeted as, oh she is Aboriginal better tiptoe around [them], you know I just wanted to be included as much as everyone else'. This account suggests that 'tippy toeing' may be a popular strategy employed by non-First Nation, White Australians to either avoid causing offence, or confronting what is a quintessentially difficult subject in Australia, with colleagues and, most likely, with clients. It reflects a wider uncertainty among these staff about how to engage with the topic of 'race' (Forrest \& Dunn, 2007; Nelson, 2013), which current research suggests, works to reinforce existing barriers to inclusive healthcare practice (Dwyer et al., 2016).

The inability to work through the tensions cultural inclusion poses for mainstream, institutional practice at $E C H$ has resulted in some staff feeling unsupported in the work they do to resist the general politics related to First Nation/non-First Nation relations. For example, one non-First Nation staff participant who works explicitly with clients from transnational groups described constantly dealing with the 'political' as the 'biggest challenge' in their role. In this interview, the practice of providing healthcare to culturally Other clients who have diverse experiences was described as political in ways that delivering healthcare in the mainstream sector is not generally perceived to be.

...it can be challenging working in an environment where other people are, other people have different focuses I guess... what we do is exceptionally political...I feel like, I think here we have to fight for our clients a lot more, and explain, explain it a 
lot more [and later] I think our client group is very judged...not just within the organisation [emphasis added]...it feels like you, you're constantly justifying why they're here and why they have the rights to the things that they have the rights to and really fighting for those rights I think (non-First Nation staff participant, refugee team).

This non-First Nation participant articulated that, in many ways, their practice deals with complex social relations informing health experiences. They further suggested that when staff across the organisation do not have this focus, or have different understandings of these social interrelationships, catering to the needs of clients and feeling supported in doing so can become a challenging, high-energy endeavour. As this non-First Nation participant articulates, the broader social and biomedical environment in which mainstream health services are embedded (Fredericks, 2010) pose many challenges for staff who are resisting dominant discourses - both societal discourses centred on particular groups of residents/clients (see Browne \& Varcoe, 2006; Downing \& Kowal, 2011; Metzl \& Hansen, 2014; Newman et al., 2013; Pedersen, Walker, Paradies, \& Guerin, 2011) and biomedical discourses related to the inconsequence of the social to clinical practice (Collyer et al., 2017). It also represents a substantive challenge to the goal of cultural inclusion in mainstream health institutions.

\section{Discussion}

Mainstream rural health services cannot be separated from the broader socio-cultural, political, historical and healthcare context in which they are situated (Waldram et al., 2006). According to Foucault (1980, p. 131), 'each society has its regime of truth, its "general politics" of truth: that is the types of discourse which it accepts and makes function as true...'. From such a perspective, discourses have a constitutive effect - they work to construct particular realities (Foucault, 1972). Foucault describes:

silence itself - the things one declines to say, or is forbidden to name, the discretion that is required between different speakers... [as] an element that functions alongside the things said... an integral part of the strategies that underlie and permeate discourse. 
Thus, what is silenced, in conjunction with what is conveyed through discourse, constructs 'the truth of reality for people', influencing their perceptions and inter(actions) (Schofield, 2015, p. 54).

The types of discourse accepted and functioning as 'true' within broader Australian society in relation to the nation as a colonised country are those that seek to legitimise the dominance of non-First Nation, specifically White, perceptions of Australia's historical and cultural truths. For example, Moreton-Robinson (2014) elucidates how, since the bicentenary, a discourse of 'loss and recuperation' has dominated, working to marginalise contestant discourses that were/are proffering alternative truths to the notion of Australian nationalism. Hage (1998) has argued that such discourses work to protect and secure a sense of belonging for colonising Australians. Yet in the context of a continuing process of colonisation, where no formal relinquishment to First Nations' sovereignty has been made, 'the presence of Indigenous people and their land, haunts[ing]' White constructions of Australia's reality 'shaking its foundations and rattling the picket fence' (Moreton-Robinson, 2014, p. 10). These underlying societal-level tensions resonated in the narratives of health workers at $E C H$. From the perspectives of First Nation participants, the current regime of truth governing First Nation/non-First Nation Australian relations constrains the ability of non-First Nation health workers to practice in ways that challenge rather than reinforce racist, discriminatory and/or prejudicial attitudes towards First Nation Australians within rural health service environments.

The leaders of this health service were, however, attempting to do just that. These non-First Nation participants were drawing on and promoting alternative discourses with which to understand the core responsibilities of rural mainstream health services that challenge dominant assumptions about who mainstream health services are for and how they should operate. These health service leaders were contesting dominant ways of thinking in 
mainstream healthcare that often support one-size-fits-all approaches to the delivery of care. The perspectives of these participants demonstrated a 'potential for diverse, local resistances and a proliferation of discourses' (Raby, 2005, p. 162) of the kind Foucault proposed is possible for generating change. For Foucault, the promotion of alternatives and the disruption of dominant discourses can work to alter perceptions of truth (Raby, 2005). Such alterations can, in turn, result in practice change (Golob \& Giles, 2013). However, in order to produce substantive social change, 'to effect a significant rupture in the dominant order', 'resistances have [to be] strategically manipulated and channelled' (Daghman, 2010, p. 17) in the daily lives of the on-the-ground staff, where 'possibilities for resistance are located' (Armstrong \& Murphy, 2012, p. 316).

It was clear that leadership was genuinely committed to creating a culturally inclusive health service. However, it was equally clear from the narratives of the other health service staff that more needs to be done to provide workers with opportunities to critically examine the cultural truths underpinning dominant practices within mainstream health services. For example, some of the discourses drawn on by non-First Nation, non-Executive staff participants reflected what Becker and Paul (2015, p. 184) describe as a 'cloaking' of racism in which 'coded language or colour-blind rhetoric' are drawn on in ways that 'protect speakers against accusations of prejudice while simultaneously reinforcing racial inequality'. Further, many of the 'stylistic mechanisms' that Bonilla-Silva (2002) proposes are used to convey racially discriminatory views whilst avoiding the label of racist, including: 'avoiding direct racial language', 'using diminishing tactics to lessen the impact of an expressed racial belief' and 'becoming verbally incoherent when discussing race', were embedded in some participant responses. Such discursive devices buttress the proliferation of biomedical discourses that presuppose the possibility of a 'neutral' subject (Collyer et al., 2017; Malatzky \& Bourke, 2017), and thus undermine the objective of cultural inclusion in healthcare. Current evidence 
suggests that, in order to confront, wrestle with and respond to institutionalised racism (Dwyer et al., 2016), an environment in which all staff feel able to express their views and to be challenged in non-confrontational ways (Pedersen et al., 2011) is needed. However, given the heightened stress and anxiety that First Nation Australians often experience from anticipating prejudicial cross-cultural interactions, which some of the accounts of First Nation staff here have articulated, it is also important that staff belonging to marginalised groups are not put in unsafe situations during this process.

\section{Conclusion}

In this article, we have aimed to elucidate the power struggles involved in prioritising the improvement of cultural inclusion within a rural mainstream health institution. Our analysis of the role discourse plays in the promotion/rejection of inclusive healthcare practice has highlighted two important effects of power relations that need to be considered and engaged with in order to stimulate the kind of substantive shift required in the mainstream sector to contest the exclusion of many culturally Other residents, including First Nation peoples, who are often disadvantaged in broader social relations and, like most other Australians, in need of multiple service options from which to receive quality health care. Firstly, the way in which Australian mainstream health services are embedded within the wider politics of truth pertaining to Australia as a White nation must be acknowledged and grappled with to effect systemic change - not health service by health service, but as part of a broader social change to race relations in Australia. This is important to ensure that the prioritisation of cultural inclusion within mainstream health services is about creating equity and choice, and that engagement in this agenda is genuine. Without a broader shift in social relations, there is every possibility that the discourse of cultural inclusion can be co-opted to 'mainstream' healthcare and eventually do away with specialist services such as ACCHOs. This would result in less choice in the primary health sector and would be a reproduction of, rather than a 
challenge to, the current regimes of truth maintaining exclusion in mainstream health services.

Secondly, our analysis suggests that the kinds of counter-discourses deployed by Executive participants' explanations for why cultural inclusion needs to be prioritised within mainstream health services represent an important act of local resistance. While these community health leaders can be seen to be 'doing their job' by prioritising the creation of a culturally inclusive environment, their enactment of discourse and thus, their exercise of power (Foucault, 1978), suggests that they are genuinely pushing the boundaries of what is expected procedurally by government and/or funding bodies. The narratives of these leaders and the way this health service operates challenge many biomedical directives that seek to standardise and medicalise the provision of healthcare (A. Levesque \& Li, 2014). Such counter-discourses need to be operationalised tactically throughout an organisation to effect a greater challenge to the dominant health institutional logics that underpin exclusionary practices within mainstream health services. Tensions and resistance, such as those that emerged amongst other staff participants in this study, need to be openly confronted, discussed and disrupted. This is critical to the 'rearrangement of power relations' (Armstrong \& Murphy, 2012, p. 317). Yet it is difficult work in institutions focused on clinical consultations, biomedical definitions of health and funding agendas, and situated within a broader social environment informed by regimes of truth/power that historically and discursively silence the realities of First Nation Peoples. In this context, a strong Executive that brings the political to the tearoom is required. It is not until the politics of race relations in (and surrounding) mainstream health are acknowledged, disrupted and re-arranged and the influence of inherently discriminatory biomedical discourses in healthcare curtailed that the health outcomes of First Nation and culturally Other groups can improve. 


\section{Disclosure Statement}

The authors declare that they have no conflict or financial interest in the application of this research.

\section{References}

Allan, B., \& Smylie, J. (2015). First Peoples, second class treatment: The role of racism in the health and well-being of Indigenous peoples in Canada. Retrieved from Toronto: http://www.wellesleyinstitute.com/wp-content/uploads/2015/02/Full-Report-FPSCTUpdated.pdf

Armstrong, N., \& Murphy, E. (2012). Conceptualizing resistance. Health: An Interdisciplinary Journal for the Social Study of Health, Illness \& Medicine, 16(4), 314-326. doi:10.1177/1363459311416832

Australian Institute of Health and Welfare. (2016). Australia's health 2014: Indigenous health. Retrieved from http://www.aihw.gov.au/australias-health/2014/indigenous-health/

Azmat, F., Fujimoto, Y., \& Rentschler, R. (2015). Exploring cultural inclusion: Perspective from a community arts organisation. Australian Journal of Management, 40(2), 375-396.

Baker, K., \& Beagan, B. (2014). Making assumptions, making space: An anthropological critique of cultural competency and its relevance to queer patients. Medical Anthropology Quarterly, 28(4), 578-598. doi:10.1111/maq.12129

Ball, S. J. (2017). Foucault as educator. London: Springer.

Becker, S., \& Paul, C. (2015). "It didn't seem like race mattered": Exploring the implications of service-learning pedagogy for reproducing or challenging color-blind racism. Teaching Sociology, 43(3), 184-200. doi:10.1177/0092055X15587987

Bloom, L. (1997). Reflections from the field - locked in uneasy sisterhood: Reflections on feminist methodology and research relations. Anthropology \& Education Quarterly, 28(1), 111-122.

Bonilla-Silva, E. (2002). The linguistics of color blind racism: How to talk nasty about blacks without sounding 'racist'. Critical Sociology, 28(1/2), 41-64.

Bourke, L., \& Geldens, P. M. (2007). Perceptions of Reconciliation and related Indigenous Issues among Young Residents of Shepparton. Australian Journal of Social Issues (Australian Council of Social Service), 42(4), 603-621.

Braun, V., \& Clarke, V. (2013). First analytic steps: Familiarisation and data coding Successful qualitative research: A practical guide for beginners (pp. 201-222). London: SAGE Publications.

Browne, A. J., \& Varcoe, C. (2006). Critical cultural perspectives and health care involving Aboriginal peoples. Contemporary Nurse: A Journal for the Australian Nursing Profession, 22(2), 155-167.

Browne, A. J., Varcoe, C., Lavoie, J., Smye, V., Wong, S. T., Krause, M., . . Fridkin, A. (2016). Enhancing health care equity with Indigenous populations: Evidence-based strategies from an ethnographic study. BMC Health Services Research, 16(1), 544-544. 
Collyer, F. M., Willis, K. F., \& Lewis, S. (2017). Gatekeepers in the healthcare sector: Knowledge and Bourdieu's concept of field. Social Science \& Medicine, 186, 96-013. doi:10.1016/j.socscimed.2017.06.004

Daghman, A. (2010). Giving a voice to the Other: Said's theory of anti-colonial resistance. (Master of Philosophy), Charles University, Prague. Retrieved from https://is.cuni.cz/webapps/zzp/download/120022453

Davis, M. (2015). Closing the gap in Indigenous disadvantage: A trajectory of Indigenous inequality in Australia Georgetown Journal of International Affairs, 16(1), 34-44.

Denzin, N., \& Lincoln, Y. (2011). The art and practices of interpretation, evaluation, and representation. In N. Denzin \& Y. Lincoln (Eds.), The SAGE handbook of qualitative research (pp. 563-567). Thousand Oaks: SAGE Publications.

Downing, R., \& Kowal, E. (2011). A postcolonial analysis of Indigenous cultural awareness training for health workers. Health Sociology Review, 20(1), 5-15.

doi:10.5172/hesr.2011.20.1.5

Dreamson, N., Thomas, G., Lee Hong, A., \& Kim, S. (2017). Policies on and practices of cultural inclusivity in learning management systems: Perspectives of Indigenous holistic pedagogies. Higher Education Research and Development, 36(5), 947-961.

Durey, A. (2010). Reducing racism in Aboriginal health care in Australia: Where does cultural education fit? Australian And New Zealand Journal Of Public Health, 34 Suppl 1, S87-S92. doi:10.1111/j.1753-6405.2010.00560.x

Durey, A. (2015). Antonio Gramsci and Pierre Bourdieu: 'Whiteness' and Indigneous healthcare. In F. Collyer (Ed.), The palgrave handbook of social theory in health, illness and medicine (pp. 191-204). New York: Palgrave Macmillan.

Dwyer, J., O'Donnell, K., Willis, E., \& Kelly, J. (2016). Equitable care for Indigenous people: Every health service can do it. Asia Pacific Journal of Health Management, 11(3), 11-17.

Forrest, J., \& Dunn, K. (2007). Constructing racism in Sydney, Australia's largest EthniCity. Urban Studies, 44(4), 699-721. doi:10.1080/00420980601185676

Foucault, M. (1972). The archaeology of knowledge and the discourse on language. New York: Pantheon Books.

Foucault, M. (1978). The history of sexuality, vol. 1: An introduction. New York: Pantheon Books.

Foucault, M. (1995). Discipline and punish: The birth of the prison (A. Sheridan, Trans. 2nd ed.). New York: Vintage Books.

Foucault, M., \& Gordon, C. (1980). Power/knowledge: Selected interviews and other writings, 1972-1977. Brighton, Sussex: Harvester Press.

Fredericks, B. (2010). What health services within rural communities tell us about Aboriginal people and Aboriginal health. Rural Society, 20(1), 10-205. doi:10.5172/rsj.20.1.10

Gavey, N. (1997). Feminist poststructuralism and discourse analysis. In M. Gergen \& S. Davis (Eds.), Toward a new psychology of gender (pp. 49-64). New York: Routledge.

Gibson, A., Lee, C., \& Crabb, S. (2016). Representations of women on Australian breast cancer websites: Cultural 'inclusivity' and marginalisation. Journal of Sociology(2), 433-452. 
Golob, M. I., \& Giles, A. R. (2013). Challenging and transforming power relations within community-based participatory research: The promise of a Foucauldian analysis. Qualitative Research in Sport, Exercise \& Health, 5(3), 356-372.

Grant, J., Parry, Y., \& Guerin, P. (2013). An investigation of culturally competent terminology in healthcare policy finds ambiguity and lack of definition. Australian And New Zealand Journal Of Public Health, 37(3), 250-256. doi:10.1111/1753-6405.12067

Hage, G. (1998). White nation: Fantasies of white supremacy in a multicultural society. Sydney: Pluto Press.

Levesque, A., \& Li, H. Z. (2014). The relationship between culture, health conceptions, and health practices: A qualitative-quantitative approach. Journal of Cross-Cultural Psychology, 45(4), 628-645.

Levesque, J.-F., Harris, M. F., \& Russell, G. (2013). Patient-centred access to health care: Conceptualising access at the interface of health systems and populations. International Journal for Equity in Health, 12(1), 18-26. doi:10.1186/1475-9276-12-18

Lupton, D. (1994). Toward the development of critical health communication praxis. Health Communication, 6(1), 55-67.

Lupton, D. (1995). The imperative of health: Public health and the regulated body. London: Sage Publications.

Macey, D. (1993). The lives of Michel Foucault : a biography. New York: Pantheon Books.

Malatzky, C., \& Bourke, L. (2017). When the social meets health in rural Australia:

Confronting the disconnect. Health Sociology Review, 26(2), 190-203.

doi:10.1080/14461242.2016.1275978

Metzl, J. M., \& Hansen, H. (2014). Structural competency: Theorizing a new medical engagement with stigma and inequality. Social Science \& Medicine, 103, 126-133. doi:10.1016/j.socscimed.2013.06.032

Moreton-Robinson, A. (2014). The house that Jack built: Britishness and white possession. Critical Race \& Whiteness Studies, 10(1), 1-12.

Murphy, E. (2003). Expertise and forms of knowledge in the government of families. The Sociological Review, 51(4), 433-462.

Nelson, J. K. (2013). Denial of racism and its implications for local action. Discourse \& Society, 24(1), 89-109. doi:10.1177/0957926512463635

Newman, C. E., Persson, A., Paquette, D. M., \& Kidd, M. R. (2013). The new cultural politics of the waiting room: Straight men, gay-friendly clinics and 'inclusive' HIV care. Sexuality Research and Social Policy, 10(2), 87-96. doi:10.1007/s13178-013-0111-z

Nikander, P. (2008). Working with transcripts and translated data. Qualitative Research in Psychology, 5(3), 225-231. doi:10.1080/14780880802314346

Pedersen, A., Walker, I., Paradies, Y., \& Guerin, B. (2011). How to cook rice: A review of ingredients for teaching anti-prejudice. Australian Psychologist, 46, 55-63.

Penman, R. (2006). Aboriginal and Torres Strait Islander views on research in their communities. Canberra: Commonwealth of Australia Retrieved from https://www.dss.gov.au/sites/default/files/documents/05 2012/op16.pdf.

Poroch, N. C. (2012). Kurunpa: Keeping spirit on country. Health Sociology Review, 21(4), 383-396. 
Raby, R. (2005). What is resistance? Journal of Youth Studies, 8(2), 151-171. doi:10.1080/13676260500149246

Richards, L. (2015). Handling qualitative data: A practical guide (3rd edition ed.). London: Sage Publications.

Riessman, C. (2000). Stigma and everyday resistance practices: Childless women in South India. Gender and Society, 14(1), 111-135.

Rubin, H., \& Rubin, I. (2012). Qualitative interviewing: The art of hearing (3rd edition ed.). California: Sage Publications.

Schofield, T. (2015). A sociological approach to health determinants. Port Melbourne: Cambridge University Press.

Waldram, J. B., Herring, D. A., \& Young, T. K. (2006) Aboriginal Health in Canada $\left(2^{\text {nd }}\right.$ edition). Toronto: University of Toronto Press. 


\section{University Library}

\section{- M M N E R VA A gateway to Melbourne's research publications}

Minerva Access is the Institutional Repository of The University of Melbourne

Author/s:

Malatzky, C;Nixon, R;Mitchell, O;Bourke, L

Title:

Prioritising the cultural inclusivity of a rural mainstream health service for First Nation Australians: an analysis of discourse and power

Date:

2018-01-01

Citation:

Malatzky, C., Nixon, R., Mitchell, O. \& Bourke, L. (2018). Prioritising the cultural inclusivity of a rural mainstream health service for First Nation Australians: an analysis of discourse and power. HEALTH SOCIOLOGY REVIEW, 27 (3), pp.248-262. https:// doi.org/10.1080/14461242.2018.1474720.

Persistent Link:

http://hdl.handle.net/11343/290215 